\title{
Methods for Caries Prevention in Children Reported by Dentists from a Brazilian Community
}

\author{
Elaine Pereira da Silva Tagliaferro ${ }^{1}$, Aylton Valsecki Júnior ${ }^{1}{ }^{(}$, Fernanda Lopez Rosell ${ }^{\circledR}$, Silvio \\ Rocha Correa da Silva ${ }^{10}$, Joseph L. Riley ${ }^{\circledR}$, Gregg H. Gilbert ${ }^{3}\left[\right.$, Valeria Veiga Gordan ${ }^{4}(\mathbb{0}$
}

\begin{abstract}
'Department of Community Dentistry, School of Dentistry, São Paulo State University, Araraquara, SP, Brazil.
${ }^{2}$ Pain Clinical Research Unit, Clinical \& Translational Science Institute, College of Dentistry, University of Florida, Gainesville, United States.

${ }^{3}$ Department of Clinical \& Community Sciences, School of Dentistry, University of Alabama at Birmingham, Birmingham, United States.

${ }^{4}$ College of Dentistry, University of Florida, Gainesville, United States.
\end{abstract}

Correspondence: Elaine Pereira da Silva Tagliaferro, School of Dentistry, Araraquara, UNESP - Sao Paulo State University, Rua Humaitá, 1680, Centro, Araraquara, SP, Brazil.14801-903. E-mail: elaine.tagliaferro@unesp.br

Academic Editor: Alessandro Leite Cavalcanti

Received: 09 April 2020 / Review: 28 August 2020 / Accepted: 02 December 2020

\footnotetext{
How to cite: Tagliaferro EPS, Valsecki Júnior A, Rosell FL, Silva SRC, Riley JL, Gilbert GH, et al. Methods for caries prevention in children reported by dentists from a Brazilian community. Pesqui Bras Odontopediatria Clín Integr. 2021 ; 21:e0070. https://doi.org/10.1590/pboci.2021.063
}

\begin{abstract}
Objective: To describe the dental practice patterns related to caries prevention in children aged 6-18 years and associated factors. Material and Methods: Dentists $(n=162)$ from Araraquara, Brazil, completed two paper questionnaires: (1) one about characteristics of their practice and their patient population; and (2) a translated version of the "Assessment of Caries Diagnosis and Caries Treatment" Questionnaire from the National Dental Practice-Based Research Network. Regression analyses were used for data analysis $(\mathrm{p}<0.05)$. Results: Dentists reported using in-office fluoride (IOF) and dental sealants (DS) in $74.2 \%$ and $45.1 \%$ of their pediatric patients, respectively. Regression analysis showed that female dentists $(\mathrm{p}=0.035$ for DS; $p=0.044$ for IOF; $p=0.011$ for non-prescription fluoride rinse), those with advanced degrees $(\mathrm{p}=0.032$ for prescription of fluoride), those who graduated from a private dental school ( $\mathrm{p}=0.018$ for chlorhexidine rinse), those who provided caries prevention regimens ( $\mathrm{p}<0.001$ for DS; $\mathrm{p}=0.004$ for IOF; $\mathrm{p}=0.013$ for nonprescription fluoride rinse), those with a greater percentage of patients interested in a caries prevention regimen $(\mathrm{p}=0.007$ for non-prescription fluoride rinse), those working in a private practice model $(\mathrm{p}=0.047$ for prescription of fluoride) were more likely to recommend some type of preventive methods to their pediatric patients. Conclusion: Dentists reported recommending IOF to most of their pediatric patients. Certain dentists', practices', and patients' characteristics were associated to some caries prevention regimens recommended by dentists.
\end{abstract}

Keywords: Dental Caries; Preventive Dentistry; Practice Patterns, Dentists'. 


\section{Introduction}

Preventive methods for caries control have benefited millions of people worldwide [1]. Caries reduction has been achieved because of the rational use of fluoride, mainly with the daily use of fluoride toothpaste [2]. The available evidence suggests that the prevalence and severity of cavitated dentine lesions have declined among 5- and 12-year-olds. Moreover, an increase in the number of teeth present at older age has been observed [1].

Conversely, groups of low socio-economic status, which may also be associated with a specific ethnicity, still have high caries levels [3]. Other variables, such as parental oral health literacy [4] and mother's schooling [5], have also been associated with higher caries prevalence.

Untreated caries in permanent teeth has affected approximately one-third of the world population and has been considered the most prevalent health condition in 2010 , and for deciduous teeth, untreated caries has affected 621 million children worldwide [6]. Therefore, the number of exceptions to the caries decline trend should be carefully examined and assessed for other preventive strategies [3].

Preventive methods used or recommended by dentists during dental visits may include dental sealants, in-office fluoride application, fluoride and chlorhexidine rinses and sugarless or xylitol chewing gum. Some studies about preventive methods used by dentists have been conducted with members of the Dental Practice-Based Research Network (DPBRN) from the United States, Scandinavian countries and Japan. Dentists from the United States, Denmark, Norway, and Sweden reported that in-office treatments (sealants and fluoride) were the most commonly used interventions for caries control in their pediatric patients [7]. Most Japanese dentists recommended in-office fluoride application for at least 50\% of their patients aged 6-18 years [8].

In Brazil, there is a scarcity of research on this topic. Therefore, the aim of this study was to describe the dental practice patterns related to caries prevention in children (defined as less than 19 years old) and factors associated with those patterns.

\section{Material and Methods}

Study Design and Sampling

The present study is part of a major cross-sectional study that assessed caries diagnosis and treatment by means of paper questionnaires among dentists from Araraquara, São Paulo State, Brazil. The major study was reviewed and approved by the Institutional Review Board (Research Ethics Committee; protocol number \#78/11). All participants provided informed consent prior to participation in the study.

The inclusion criteria for the present study were dentists who: a) currently treats dental caries; b) currently practices in Araraquara; c) are not retired; and d) reports that at least $10 \%$ of their patients are 18 years of age or younger.

The sample size for the present study was determined by the number of participants who received and filled out the questionnaires during data collection (October/2014 to December/2015) and met the inclusion criteria, adding up 162 dentists.

\section{Data Collection}

Two paper questionnaires were sent to dentists: (a) one about characteristics of their practice and patient population; and (b) a translated version of the "Assessment of Caries Diagnosis and Caries Treatment" Questionnaire from the U. S. National Dental PBRN. The translation and cultural adaptation process, 
performed according to Guillemin et al. [9], as well as the Brazilian version of the questionnaire have been published elsewhere [10].

Detailed information on the recruitment process and strategies to increase the response rate (pre-paid return envelope, questionnaires sent to work address; a second copy of the questionnaire to non-respondents; precontact by telephone; collection of completed questionnaires at work address) for the major study is described in a previous paper [11].

Table 1 presents the series of questions about the use of caries preventive methods in pediatric patients and questions about individualized caries preventive treatment regimen.

Table 1. Questions asked to participating dentists about caries prevention, caries risk assessment, and individualized preventive treatment.

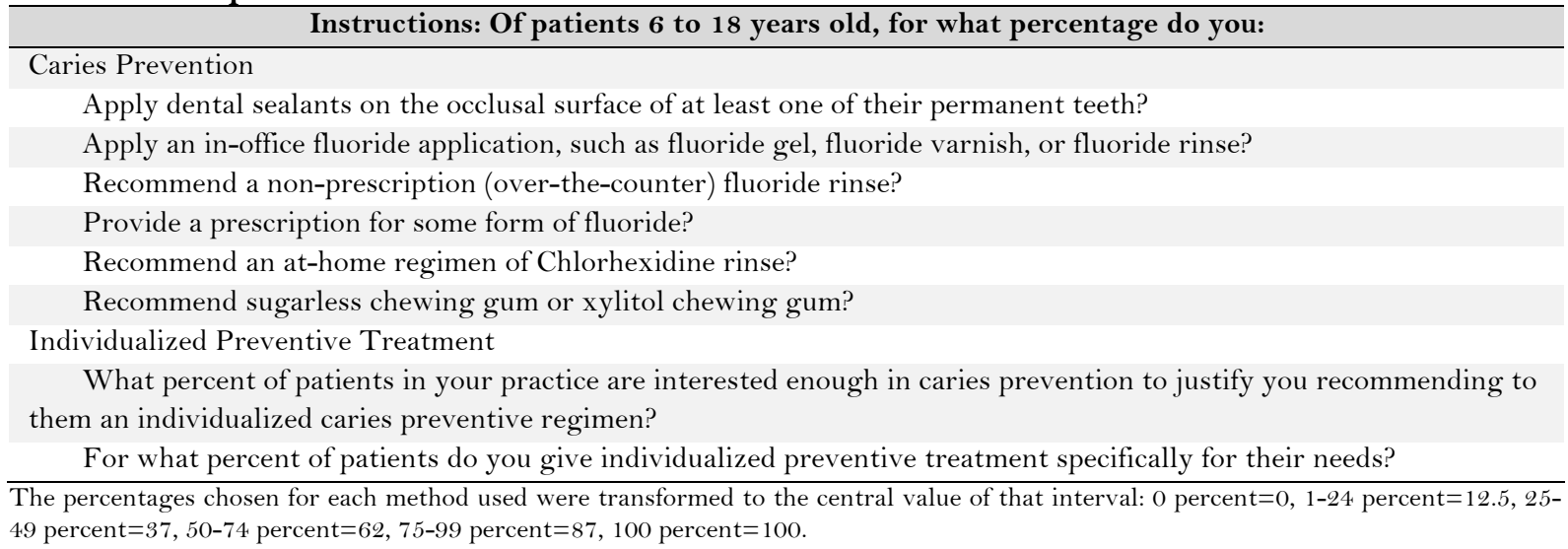

Practitioner and practice characteristics were tested as predictors of use for each caries prevention agent for pediatric patients using the general linear model. Comparisons were considered statistically significant if p-values were less than 0.05 .

Practitioner variables that included dentist gender (male $=0$ and female $=1)$, years since dental school graduation, dental school attended as private or public (public $=0$ and private $=1$ ), specialization training in pediatrics completed (general dentistry $=0$ and pediatric specialization $=1$ ), an advanced degree (no advanced degree $=0$, master's $=1$, doctorate $=2$ ) were entered in step 1 . In a second step, practice variables were tested as predictors of use for each caries prevention agent in pediatric patients.

These included the percentage of patients that are 18 years of age or younger and whether an exclusively private practice model was used (public health or hybrid private/public health models $=0$, private $=1$ ) along with questions about caries diagnosis, whether caries risk was assessed (not performing caries risk assessment $=0$ and performing caries risk assessment $=1$ ), and percentage of patients who desire and who receive individualized caries prevention.

\section{Data Analysis}

Practitioner characteristics that were significant at $\mathrm{p}<0.10$ were carried forward in each model. A stepwise entry model was used in each analysis with entry set at 0.10 and removal at 0.15 for all regression analyses as there was no theoretical or logical rationale for variable entry priority [12].

For variables where percentages were asked, responses were transformed from the interval selected to the central value of that interval to enhance interpretation and so that parametric statistics could be used: $0 \%=0 \%, 1-24 \%=12.5 \%, 25-49 \%=37 \%, 50-74 \%=62 \%, 75-99 \%=87 \%, 100 \%=100 \%$. Power analysis for regression 
revealed that with 5 predictors and testing at a critical value of 0.05 , a sample of 157 provided power of 0.8 to detect an effect of $\mathrm{f}^{2}=0.8$.

\section{Results}

From a list of 801 dentists, 164 did not receive the questionnaires due to outdated addresses, 277 were not found by phone and we could not confirm if the questionnaires were received, 30 refused to participate, 113 were deemed not eligible after the potential respondent communicated with the research team about eligibility status, 217 were considered participants for the major study and data from 162 dentists were analyzed in the present study (Figure 1).

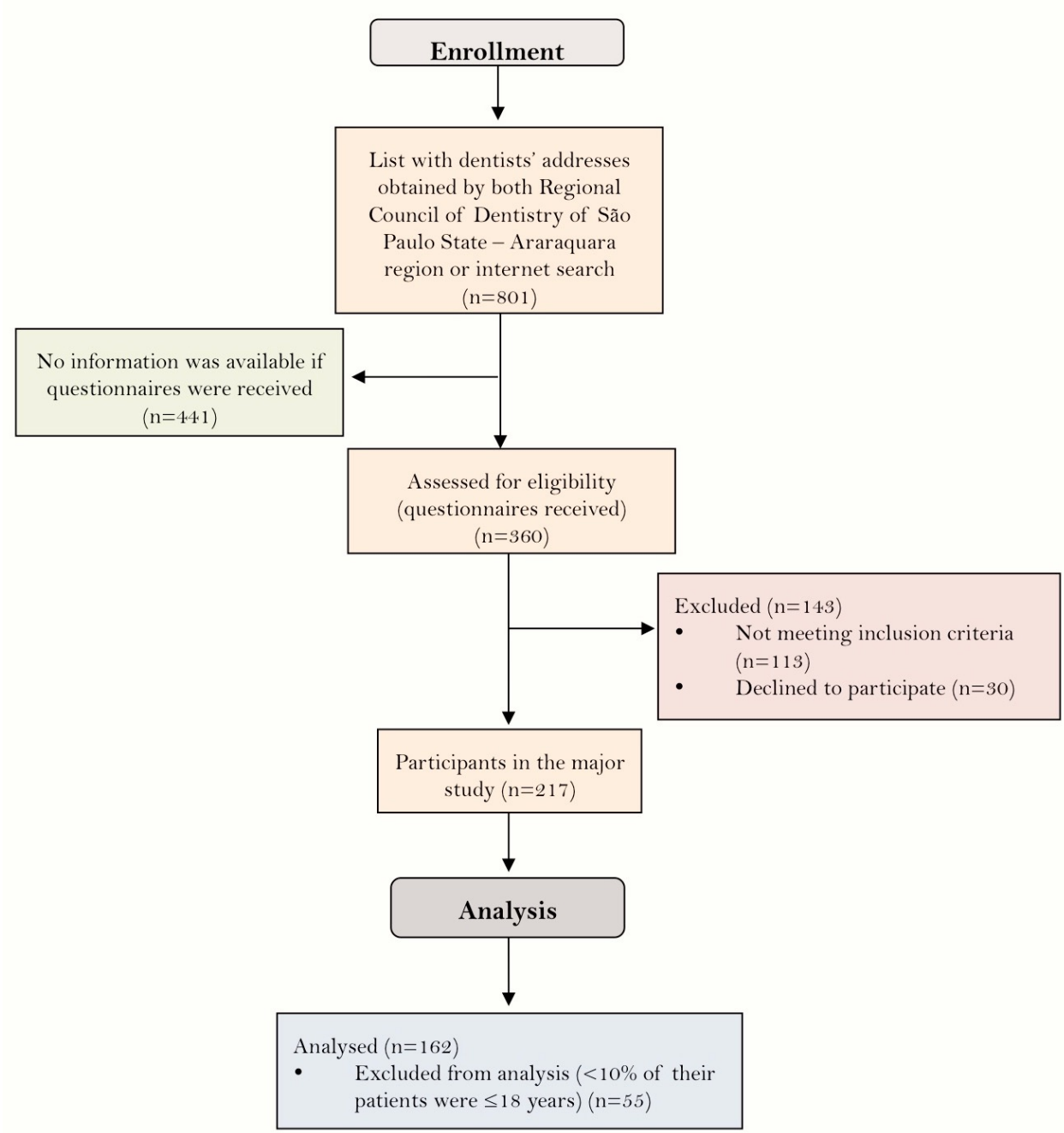

Figure 1. Flowchart showing the participation of dentists in the study.

The 162 dentists included in this set of analyses did not differ from the 55 dentists who were excluded from the original sample of 217 because they reported $<10 \%$ of their patients were 18 years of age or younger on any of the practitioner and practice characteristics listed in Table 2.

Most participants were female (62\%), studied in public dental school (76\%) and completed some type of specialization training (65\%). Their mean age and mean years since dental school graduation were 42.8 and 20.3 years, respectively (Table 2 ). 
Table 2. Dentist and practice characteristics.

\begin{tabular}{|c|c|}
\hline Variables & $\mathbf{N}(\%)$ \\
\hline Age of Dentist (Mean and SD) & $42.8( \pm 12)$ \\
\hline Gender (female) & $101(62.0)$ \\
\hline \multicolumn{2}{|l|}{ Type of Practice } \\
\hline Private Practice & $79(49.0)$ \\
\hline Private/Public Hybrid & $43(27.0)$ \\
\hline Public Service & $31(19.0)$ \\
\hline Other & $9(6.0)$ \\
\hline Years Since Dental School Graduation (Mean and SD) & $20.3( \pm 11.6)$ \\
\hline \multicolumn{2}{|l|}{ Type of Dental School } \\
\hline Public Institution & $123(76.0)$ \\
\hline Private Institution & $39(24.0)$ \\
\hline \multicolumn{2}{|l|}{ Specialization } \\
\hline Not Completed Specialization Training & $57(35.0)$ \\
\hline Specialization Training (Not Pediatric) & $88(54.0)$ \\
\hline Pediatric Specialization & $17(11.0)$ \\
\hline \multicolumn{2}{|l|}{ Advanced Degree } \\
\hline No Advanced Degree & $115(71.0)$ \\
\hline Master’s Degree & $10(6.0)$ \\
\hline Doctorate & $37(23.0)$ \\
\hline \multicolumn{2}{|l|}{ Percent of Patients 1-18 Years of Age } \\
\hline $50 \%$ or Greater Pediatric Patients & $26(15.0)$ \\
\hline $30 \%$ or Greater Pediatric Patients & $56(31.0)$ \\
\hline $10 \%$ to $29 \%$ Pediatric Patients & $80(54.0)$ \\
\hline Percent of Patients who are Interested in Caries Prevention (Mean and SD) & $45 \%( \pm 25)^{*}$ \\
\hline $\begin{array}{l}\text { Percent of Patients who Receive Individualized Preventive Treatment } \\
\text { Specifically for their Needs (Mean and SD) }\end{array}$ & $58 \%( \pm 34)^{*}$ \\
\hline
\end{tabular}

Table 3 summarizes the frequency of use of caries prevention methods by dentists who reported using in-office fluoride in most of their pediatric patients $(74.2 \%)$. Sealant application was reported to be performed in $45.1 \%$ of their pediatric patients.

Table 3. Frequency of use of specific caries prevention methods for pediatric patients.

\begin{tabular}{lcc}
\hline \multicolumn{1}{c}{ Preventive Agent } & Mean \% (SD) & $\mathbf{9 5 \% ~ C I ~}$ \\
\hline Dental Sealant & $45.1 \%(\mathrm{SD}=34)$ & $42.3-47.9$ \\
In-office Fluoride & $74.2 \%(\mathrm{SD}=33)$ & $71.7-76.7$ \\
Non-prescription Fluoride & $17.7 \%(\mathrm{SD}=29)$ & $15.5-19.9$ \\
Prescription Fluoride & $18.6 \%(\mathrm{SD}=27)$ & $16.5-20.7$ \\
Chlorhexidine Rinse & $17.3 \%(\mathrm{SD}=19)$ & $15.6-18.8$ \\
Xylitol Gum & $16.6 \%(\mathrm{SD}=32)$ & $14.1-19.1$ \\
\hline
\end{tabular}

The percentages chosen for each method used were transformed to the central value of that interval: 0 percent $=0$, $1-24$ percent $=12.5,25-49$ percent $=37,50-74$ percent $=62,75-99$ percent $=87$, 100 percent $=100$.

Table 4 shows results from the linear regressions done; showing the parameter estimates for both dentist and practice characteristics associated with the frequency of use of caries prevention methods in pediatric patients.

In relation to dentist characteristics, female dentists reported applying dental sealants $(\mathrm{p}=0.035)$, recommending a non-prescription fluoride rinse $(\mathrm{p}=0.011)$ and applying an in-office fluoride application $(p=0.044)$ to a significantly higher percentage of their pediatric patients than male dentists.

Dentists with an advanced degree reported providing a prescription for some form of fluoride more often than dentists without an advanced degree $(\mathrm{p}=0.032)$. Dentists who graduated from a private dental 
school reported recommending an at-home regimen of chlorhexidine rinse to a larger percentage of their pediatric patients than dentists who graduated from a public dental school $(\mathrm{p}=0.018)$.

Concerning to practice characteristics and caries management, dentists who reported providing a caries prevention regimen also were more likely to recommend dental sealant application $(\mathrm{p}<0.001)$ and an inoffice fluoride application $(\mathrm{p}=0.004)$.

Dentists who reported providing a caries prevention regimen $(p=0.013)$ and having a greater percentage of patients interested in a caries prevention regimen $(\mathrm{p}=0.007)$ were more likely to recommend a non-prescription fluoride rinse. Dentists who reported using an exclusively private practice model were more likely to provide a prescription for some form of fluoride than dentists using other practice models $(p=0.047)$.

Table 4. Parameter estimates for dentist and practice characteristics associated with each caries prevention method.

\begin{tabular}{|c|c|c|c|}
\hline Preventive Methods $^{\dagger}$ & $\mathbf{B}$ & SE & p-value \\
\hline \multicolumn{4}{|l|}{ Dental Sealants } \\
\hline Dentist Gender (Female) & 12.922 & 6.071 & 0.035 \\
\hline Percent of Patients who Receive Caries Prevention Regimen & 0.332 & 0.082 & $<0.001$ \\
\hline \multicolumn{4}{|l|}{ Final model fit $(\mathrm{F}=3.297, \mathrm{p}=0.005)^{\circ}$} \\
\hline \multicolumn{4}{|l|}{ In-office Fluoride } \\
\hline Dentist Gender (Female) & 9.854 & 5.012 & 0.044 \\
\hline Practice Model (Private) & -10.620 & 5.035 & 0.053 \\
\hline Occlusal Explorer & 0.118 & 0.067 & 0.073 \\
\hline Percent of Patients who Receive Caries Prevention Regimen & 0.239 & 0.080 & 0.004 \\
\hline \multicolumn{4}{|l|}{ Final model fit $(\mathrm{F}=3.124 \mathrm{p}=0.007)$} \\
\hline \multicolumn{4}{|l|}{ Non-prescription Fluoride } \\
\hline Dentist Gender (Female) & 12.695 & 4.900 & 0.011 \\
\hline Percent of Patients who Receive Caries Prevention Regimen & 0.184 & 0.072 & 0.013 \\
\hline Percent of Patients who are Interested in a Caries Prevention Regimen & 0.292 & 0.113 & 0.007 \\
\hline \multicolumn{4}{|l|}{ Final model fit $(\mathrm{F}=2.957, \mathrm{p}=0.010)$} \\
\hline \multicolumn{4}{|l|}{ Prescription Fluoride } \\
\hline Advanced Degree Awarded & 5.518 & 2.557 & 0.032 \\
\hline Practice Model (private) & 8.462 & 4.079 & 0.047 \\
\hline \multicolumn{4}{|l|}{ Final model fit $(\mathrm{F}=2.521, \mathrm{p}=0.028)$} \\
\hline \multicolumn{4}{|l|}{ Chlorhexidine Rinse } \\
\hline Type of Dental School (Private) & 8.350 & 3.505 & 0.018 \\
\hline \multicolumn{4}{|l|}{ Final model fit $(\mathrm{F}=2.621, \mathrm{p}=0.023) \ddagger$} \\
\hline \multicolumn{4}{|l|}{ Sugarless or Xylitol Gum } \\
\hline Years since Graduation from Dental School & 0.421 & 0.269 & 0.095 \\
\hline Specialization Training & -5.365 & 3.004 & 0.085 \\
\hline \multicolumn{4}{|l|}{ Final model fit $(\mathrm{F}=1.767, \mathrm{p}=0.125) \ddagger$} \\
\hline
\end{tabular}

\section{Discussion}

This paper presented results on caries prevention practices reported by a group of dentists in Araraquara, Brazil, using the translated and culturally adapted questionnaire from the National Dental Practice-Based Research Network.

The results revealed that most dentists who participated in the present study and reported that at least $10 \%$ of their patients are 18 years of age or younger were female. The majority (85\%) of Brazilian dentists with specialization in pediatric dentistry are female [13] and a Brazilian study revealed that a significantly higher number of female dentists who graduated from a public university choose the pediatric dentistry specialty in comparison to their male counterparts [14]. Other results also showed that most participating 
dentists completed their dental degree from a public dental school and completed some type of specialization training, indicating a sample with a specialized profile.

Dentists reported using in-office fluoride in most of their pediatric patients (74.2\%). These results are similar to those found by Riley et al. [7] in that in-office fluoride was the most commonly used procedure for caries prevention in children and higher that those reported in Japan, where $54 \%$ of dentists reporting using in-office fluoride application to more than $50 \%$ of patients aged 6-18 years [8] and in adult patients in the United States [15].

Despite several ecological preventive approaches having been developed for caries prevention, fluoride remains the most cost-effective preventive agent and will continue to be the mainstream of any caries prevention protocol [16]. Regular toothbrushing with 1000-1100 ppm fluoride toothpaste has been considered an effective measure for preventing dental caries [17].

According to the American Dental Association (ADA), the clinical recommendations for patients 6 years or older who are at high caries risk are: professionally applied 2.26\% fluoride varnish every 3-6 months or $1.23 \%$ fluoride (APF) gel professionally applied for 4 minutes every 3-6 months; home-use of 0.09\% fluoride mouth rinse at least weekly, or home-use of $0.5 \%$ fluoride gel or paste twice daily. For children younger than 6 years, the ADA recommends only 2.26\% fluoride varnish professionally applied every 3-6 months [18].

The Brazilian Association of Pediatric Dentistry recommends performing individualized caries risk assessment prior to the use of fluoride-containing products. They also suggested additional fluoride therapy for high-risk individuals, e.g., children with either orthodontic appliances, with reduced salivary function, unable to properly clean teeth, consuming a cariogenic diet, with mothers or siblings with caries or with high levels of cariogenic bacteria or with active caries [19].

The results of the current study also showed that dentists reported applying dental sealants on the occlusal surface of at least one of the permanent teeth in nearly half of their pediatric patients, which is lower than the percentage found by Riley et al. [7] in that on average $69 \%$ of pediatric patients received dental sealants.

Dentists from the Japanese Dental Practice-Based Research Network were asked to select the treatment decision for the occlusal surface of a mandibular first molar with increasing depths of cavitation (clinical photographs) in which sealants would be the most appropriate treatment for high caries risk 12-yearold children. They recommended sealants in $16 \%$ to $26 \%$ of cases, which was indicated by the authors as rather low, based on indications for sealants by the American Dental Association [8].

A recent systematic review comparing the effects of fissure sealants in preventing dental caries in occlusal surfaces of permanent teeth in children and adolescents showed that resin-based sealants are effective, reducing caries by $11 \%$ to $51 \%$ compared to no sealant, after 2 years of follow-up with similar benefits up to 4 years [20]. Even though they are an effective method and a less-invasive preventive procedure [21], their long-term success depends on reapplication [22,23], and they are part of a comprehensive prevention program that should include daily brushing and a healthy diet [22,24].

Regression analysis showed that the following variables were predictors of the recommendation of some type of preventive measures: dentist gender, percent of patients who receive or are interested in a caries prevention regimen, practice model, advanced degree, and type of dental school.

Female dentists apply dental sealants, in-office fluoride, as well as recommend a non-prescription fluoride rinse to pediatric patients to a higher percentage compared to male dentists, suggesting that female participants are more likely to provide preventive procedures. 
Findings on gender differences in caries management are not consensual and future research is needed to address this issue. Data from the Dental Practice-Based Research Network in the United States found differences between male and female dentists regarding diagnosis and treatment of dental caries. According to their results, female dentists are more likely to treat earlier stages of dental caries with preventive therapy and recommend at-home fluoride to their patients than male dentists [25].

Conversely, in-office fluoride for pediatric patients is the main treatment reported by male dentists [25]. In another study, female dentists (74\%) were more likely to use dental sealants than male dentists (67\%) [7]. Japanese DPRBN dentists showed no differences between gender when reporting their practice patterns for caries prevention [8,26].

A study among dentists from the Southern Brazilian State of Santa Catarina observed that decisionmaking for restoring dental caries as seen in radiographs was not associated with gender, age and years of practice [27].

In Brazil, there has been an evident increase in women entering the dental profession. Almost 90\% of dentists were male in the 1960s; current data show that most dentists (54\%) are female [28]. It has been suggested that the feminization of dentistry in Brazil can lead to a more-preventive/conservative practice target to oral health promotion and people's well-being in contrast to traditional dentistry based on curative and surgical procedures [29].

Dentists who reported a greater percentage of patients receiving caries prevention regimen were more likely to recommend dental sealant application, in-office fluoride application and non-prescription fluoride rinse. Our results differ from the Japanese DPBRN study, which showed that dental procedure characteristics such as percentage of patients receiving hygiene instruction or dietary advice were not associated with the recommendation of in-office fluoride to $50 \%$ or more of pediatric patients [8].

Most dentists in the present study were female (62\%); the opposite was found in the Japanese study, where $82 \%$ of dentists were male [8]. Our finding that female dentists reported applying/recommending a higher percentage of preventive agents to a higher percentage of pediatric patients than males may explain these differences between Brazilian and Japanese dentists.

Dentists who have a greater percentage of patients interested in a caries prevention regimen reported recommending a non-prescription fluoride rinse to a higher percentage of their pediatric patients. Findings from Japan DPBRN revealed that the percentage of patients interested in caries prevention was significantly associated with whether the dentist recommended in-office fluoride application to their patients aged 6-18 years old [8].

Other variables were associated with the recommendation of some type of preventive treatment to a significantly higher percentage of pediatric patients, such as: private practice model (prescription fluoride), advanced degree awarded (prescription fluoride), and graduating from a private dental school (chlorhexidine).

Patients from a private practice model in Brazil generally are from high socio-economic status compared to patients from public services or from a dental health plan. It is possible that higher-socioeconomic status patients need fewer restorative procedures and dentists perform preventive procedures mainly, which could explain the results that a private practice model was a predictor for some type of a caries preventive regimen.

A recent study showed that despite the increase in public dental services coverage, government funding, human resources and infrastructure, the use of public dental services remained stable during the fiveyear period of $2003-2008$, with only a slight increase (29.7\% in 2003 to $30.7 \%$ in 2008 ), while private service utilization increased from $64.4 \%$ in 2003 to $74.3 \%$ in 2013 [28]. 
Another predictor for recommending a preventive caries regimen was having an advanced degree. Considering that current caries management should be based on a preventive, conservative and evidence-based perspective (individual risk assessment, active surveillance, oral health literacy, and preventive therapies and/or surgical treatment) [30], it is expected that dentists with advanced training might be more likely to use an evidence-based approach to routine care, thereby providing caries preventive therapies adequately.

Dentists who graduated from a private dental school reported recommending an at-home regimen of chlorhexidine rinse to a larger percentage of their pediatric patients than dentists who graduated from a public dental school.

Evidence-based studies have not recommended chlorhexidine products for coronal caries prevention [31]. Furthermore, little evidence exists for effectiveness of chlorhexidine in caries prevention or in reduction of mutans streptococci levels in children and adolescents [32].

A Brazilian study verified that students from private dental schools chose to restore enamel lesions in a higher proportion than did students from public schools [33], suggesting a more-conservative profile of students from public schools. Based on our results and past literature findings, we can speculate that a gap between evidence and practice could be more present among dentists from private schools. Further studies are need to clarify this conjecture.

This study has certain limitations. From a statistical perspective, cross-sectional designs have limited inferential power and the sample comprised a self-selected group of dentists. The questionnaire design of the study works under the assumption that what dentists accurately reported their practice patterns doing in practice is actually what they perform routinely in their dental practices; c) dentists were asked about their overall preventive measures, not whether they gave individual patients recommendations for single or multiple treatments [25]; and d) the questions measured self-reported preventive procedures that may be influenced by social desirability and recall bias [15]. Nonetheless, the study proved to be a feasible tool to study dental practice patterns and it can be used to compare the results to other dentist populations [11].

\section{Conclusion}

Dentists reported using in-office fluoride application in most of their pediatric patients. The results also suggested that female dentists have a more-preventive profile than male dentists and that private practice model, advanced degree, graduation from a private dental school and greater percentage of patients who receive or are interested in a caries prevention regimen were associated with dentists recommending some type of preventive measures to a significantly higher percentage of their pediatric patients.

\section{Authors' Contributions}

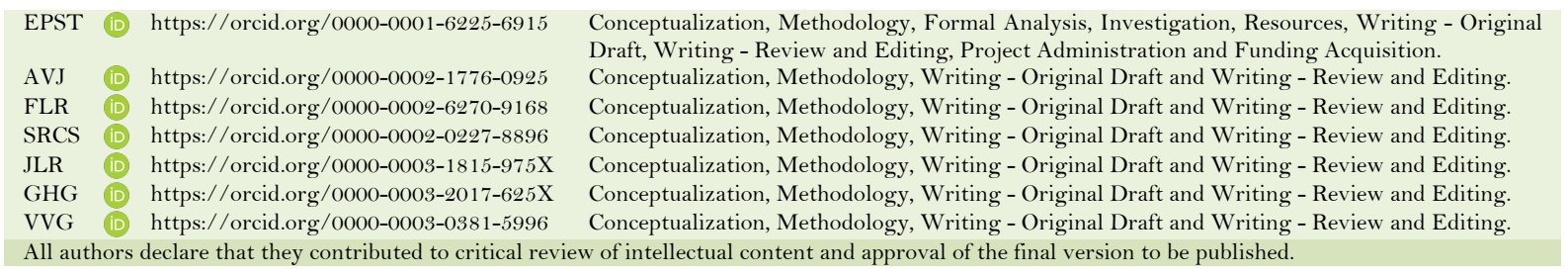

\section{Financial Support}

Financial support was provided by the Foundation for the Development of the São Paulo State University (FUNDUNESP; Grant 0170/004/13-PROPe/CDC) and by The São Paulo Research Foundation (FAPESP; Grant 2012/10397-2). Certain components of this work were supported by the National Institutes of Health (Grants U01- DE-16746, Uo1-DE-16747 and U19-DE-22516). Opinions and 
assertions contained herein are those of the authors and are not to be construed as necessarily representing the views of the respective organizations or of the National Institutes of Health. NIDCR had no role in the study design, data collection and analysis, decision to publish, or preparation of the manuscript.

\section{Conflict of Interest}

The authors declare no conflicts of interest.

\section{Data Availability}

The data used to support the findings of this study can be made available upon request to the corresponding author.

\section{Acknowledgments}

The authors thank Claudia Huck, Fabiano Jeremias, Juliana Alvares Duarte Bonini Campos, Mariana de Matos, Luana Moreira Loures Ridolfi, Wilson Chediek, Elina Mara da Silva Marcomini, Rita De Cassia Prando, Márcia Santana, Luis Alberto da Silva, Ivanete Correa Macieira, Célia Regina de Freitas Rocha, Olavo Bergamaschi Barros and Karina Antunes for their assistance and dentists who participated in this study.

\section{References}

[1] Frencken JE, Sharma P, Stenhouse L, Green D, Laverty D, Dietrich T. Global epidemiology of dental caries and severe periodontitis - a comprehensive review. J Clin Periodontol 2017; 44(Suppl 18):S94-S105. https://doi.org/10.1111/jcpe.12677

[2] Pitts NB, Zero DT, Marsh PD, Ekstrand K, Weintraub JA, Ramos-Gomez F, et al. Dental caries. Nat Rev Dis Primers 2017; 3:17030. https://doi.org/10.1038/nrdp.2017.30

[3] Splieth CH, Christiansen J, Page LAF. Caries epidemiology and community dentistry: chances for future improvements in caries risk groups. Outcomes of the ORCA Saturday Afternoon Symposium, Greifswald, 2014. Part 1. Caries Res 2016; 50(1):9-16. https://doi.org/10.1159/000442713

[4] Firmino RT, Martins CC, Faria LS, Martins Paiva S, Granville-Garcia AF, Fraiz FC, et al. Association of oral health literacy with oral health behaviors, perception, knowledge, and dental treatment related outcomes: a systematic review and meta-analysis. J Public Health Dent 2018; 78(3):231-45. https://doi.org/10.1111/jphd.12266

[5] Pinto-Sarmento TCA, Abreu MH, Gomes MC, Costa EMMB, Martins CC, Granville-Garcia AF, et al. Determinant factors of untreated dental caries and lesion activity in preschool children using ICDAS. PLoS ONE 2016; 11(2):e0150116. https://doi.org/10.1371/journal.pone.0150116

[6] Kassebaum NJ, Bernabé E, Dahiya M, Bhandari B, Murray CJ, Marcenes W. Global burden of untreated caries: a systematic review and meta regression. J Dent Res 2015; 94(5):650-8. https://doi.org/10.1177/0022034515573272

[7] Riley JL, Richman JS, Rindal DB, Fellows JL, Qvist V, Gilbert GH, et al. Dental PBRN Collaborative Group. Use of caries-preventive agents in children: findings from the dental practice-based research network. Oral Health Prev Dent 2010; 8(4):351-9.

[8] Yokoyama Y, Kakudate N, Sumida F, Matsumoto Y, Gilbert GH, Gordan VV. Evidence-practice gap for in-office fluoride application in a Dental Practice-based Research Network. J Public Health Dent 2016; 76(2):91-7. https://doi.org/10.1111/jphd.12114

[9] Guillemin F, Bombardier C, Beaton D. Cross-cultural adaptation of health-related quality of life measures: literature review and proposed guidelines. J Clin Epidemiol 1993; 46(12):1417-32.

https://doi.org/10.1016/0895-4356(93)90142-n

[10] Tagliaferro EPS, Ridolfi LML, Matos M, Rosell FL, Valsecki Junior A, Silva SRC, et al. Translation and Brazilian adaptation of the "Assessment of caries diagnosis and caries treatment". Arq Odontol 2017; 53:1-15.

[11] Tagliaferro EPS, Valsecki Junior A, Rosell FL, Silva SRC, Riley JL, Gilbert GH, et al. Caries diagnosis in dental practices: results from dentists in a Brazilian community. Oper Dent 2019; 44(1):E23-31. https://doi.org/10.2341/18-034-C

[12] Cohen J, Cohen P. Applied Multiple Regression/Correlation Analysis for the Behavioral Sciences. Hillsdale: Lawrence Erlbaum Associates; 1983. 545p.

[13] Morita C, Haddad AE, Araújo ME. Current Profile and Trends of Brazilian Dentists. Maringá: Dental Press; 2010. $96 \mathrm{p}$.

[14] Nunes MF, Leles CR, Gonçalves MM. Gender and choice for dental specialties: study of a public university students. Robrac 2010; 19(49):142-5.

[15] Riley JL, Gordan VV, Rindal DB, Fellows JL, Ajmo CT, Amundson C, et al. Dental PBRN Collaborative Group. Preferences for caries prevention agents in adult patients: findings from the dental practice-based research network. Community Dent Oral Epidemiol 2010; 38(4):360-70. https://doi.org/10.1111/j.1600-0528.2010.00547.x

[16] Philip N, Suneja B, Walsh LJ. Ecological approaches to dental caries prevention: paradigm shift or shibboleth? Caries Res 2018; 52(1-2):153-65. https://doi.org/10.1159/000484985 
[17] Walsh T, Worthington HV, Glenny AM, Marinho VC, Jeroncic A. Fluoride toothpastes of different concentrations for preventing dental caries. Cochrane Database Syst Rev 2019; 3(3):CDo07868. https://doi.org/10.1002/14651858.CDo07868.pub3

[18] Marinho VC. Applying prescription-strength home-use and professionally applied topical fluoride products may benefit people at high risk for caries - the American Dental Association (ADA) 2013 clinical practice guideline recommendations. J Evid Based Dent Pract 2014; 14(3):120-3. https://doi.org/10.1016/j.jebdp.2014.07.011

[19] Noronha JC, Myaki SI, Paiva SM. Fluoride Use. In: Brazilian Association of Pediatric Dentistry. Reference Manual for Clinical Procedures in Pediatric Dentistry. 2009. [Available from: https://www.abodontopediatria.org.br/manual1/Capitulo-9-Utilizacao-do-Fluoreto.pdf]. [Accessed on January 22, 2020]. [In Portuguese].

[20] Ahovuo-Saloranta A, Forss H, Walsh T, Nordblad A, Mäkelä M, Worthington HV. Pit and fissure sealants for preventing dental decay in permanent teeth. Cochrane Database Syst Rev 2017; 7(7):CDo01830. https://doi.org/10.1002/14651858.CD001830

[21] Wong A, Subar PE, Young DA. Dental caries: an update on dental trends and therapy. Adv Pediatr 2017; 64(1):30730. https://doi.org/10.1016/j.yapd.2017.03.011

[22] Naaman R, El-Housseiny AA, Alamoudi N. The use of pit and fissure sealants - a literature review. Dent J 2017; 5(4):34. https://doi.org/10.3390/dj5040034

[23] Cvikl B, Moritz A, Bekes K. Pit and fissure sealants - a comprehensive review. Dent J 2018; 6(2):18. https://doi.org/10.3390/dj6020018

[24] Colombo S, Ferrazzano GF. Dental sealants. Part 2: Who should get dental sealants and when. Eur J Paediatr Dent 2018; 19(2):165-6. https://doi.org/10.23804/ejpd.2018.19.02.13

[25] Riley JL, Gordan VV, Rouisse KM, McClelland J, Gilbert GH. Dental Practice-Based Research Network Collaborative Group. Differences in male and female dentists' practice patterns regarding diagnosis and treatment of dental caries: findings from The Dental Practice-Based Research Network. J Am Dent Assoc 2011; 142(4):429-40. https://doi.org/10.14219/jada.archive.2011.0199

[26] Yokoyama Y, Kakudate N, Sumida F, Matsumoto Y, Gilbert GH, Gordan VV. Dentists' practice patterns regarding caries prevention: results from a dental practice-based research network. BMJ Open 2013; 3(9):e003227. https://doi.org/10.1136/bmjopen-2013-003227

[27] Traebert J, Wesolowski CI, Lacerda JT, Marcenes W. Thresholds of restorative decision in dental caries treatment among dentists from small Brazilian cities. Oral Health Prev Dent 2007; 5(2):131-5.

[28] Chaves SCL, Almeida AMFL, Rossi TRA, Santana SF, Barros SG, Santos CML. Oral health policy in Brazil between 2003 and 2014: scenarios, proposals, actions, and outcomes. Cien Saude Colet 2017; 22(6):1791-803. https://doi.org/10.1590/1413-81232017226.18782015

[29] Kfouri MG, Moyses SJ, Moyses ST. Women's motivation to become dentists in Brazil. J Dent Educ 2013; 77(6):8106.

[30] Slayton RL, Fontana M, Young D, Tinanoff N, Novy B, Lipman RD, et al. Dental caries management in children and adults. NAM Perspectives. Discussion Paper, National Academy of Medicine, Washington, DC. https://doi.org/10.31478/201609d

[31] Rethman MP, Beltrán-Aguilar ED, Billings RJ, Hujoel PP, Katz BP, Milgrom P, et al. American Dental Association Council on Scientific Affairs Expert Panel on Nonfluoride Caries-Preventive Agents. Non-fluoride caries-preventive agents: executive summary of evidence-based clinical recommendations. J Am Dent Assoc 2011; 142(9):1065-71. https://doi.org/10.14219/jada.archive.2011.0329

[32] Walsh T, Oliveira-Neto JM, Moore D. Chlorhexidine treatment for the prevention of dental caries in children and adolescents. Cochrane Database Syst Rev 2015; 4:CDo08457. https://doi.org/10.1002/14651858.CDo08457.pub2

[33] Bervian J, Tovo MF, Feldens CA, Brusco LC, Rosa FM. Evaluation of final-year dental students concerning therapeutic decision making for proximal caries. Braz Oral Res 2009; 23(1):54-60.

https://doi.org/10.1590/s1806-83242009000100010 